\title{
Nonconvulsive Status Epilepticus in Adults: Types, Pathophysiology, Epidemiology, Etiology, and Diagnosis
}

cc
Author
Stephan Rüegg
Affiliation
Department of Clinical Neurology, University Hospital Basel, Basel,
Switzerland
Key words
nonconvulsive status epilepticus, coma, encephalopathy behavioral
changes, EEG
Bibliography
Dol http://dx.doi.org/10.1055/s-0043-103383
Neurology International Open 2017; 1: E189-E203
C Georg Thieme Verlag KG Stuttgart · New York
ISSN $2511-1795$
Correspondence
Stephan Rüegg
Abteilung für Klinische Neurophysiologie
Neurologische Klinik
Universitätsspital Basel
Petersgraben 4
CH-4031 Basel
Switzerland
Stephan.Rueegg@usb.ch

\begin{abstract}
Nonconvulsive status epilepticus (NCSE) is defined by permanent electroclinical nonconvulsive epileptic activity or a series of nonconvulsive seizures without recovery to baseline. This "silent" manifestation of lasting neurological symptoms, like aphasia, confusion, etc., impedes easily recognizing NCSE. The most important diagnostic step often is to consider the possibility of NCSE. NCSE can only be confirmed by an immediate EEG recording. Epidemiological studies show slight preponderance of convulsive status epilepticus (CSE) over NCSE (60:40\%); however, this might result from lack of recognition of NCSE because of its very unspectacular manifestation. Regarding pathophysiology, the neuronal mechanisms are identical for both NCSE and CSE, but they spare the primary motor neurons. Permanent hyperexcitability may damage the neurons involved in NCSE the same way as the motor neurons in CSE. However, NCSE is spared from the life-threatening secondary pathophysiological sequelae of CSE (lactic acidosis, respiratory exhaustion, rhabdomyolsis, etc.). Nevertheless, autonomic dysregulation (arrhythmias (ventricular tachycardia/asystolia), apneas) may also expose the patient to substantial acute risks. There are a myriad of causes for NCSE and they are mainly medication errors (insufficient adherence or addition of new drugs with interactions) in patients with known epilepsy. In these patients and in those without known epilepsy, other causes include metabolic, toxic, structural (tumors, hemorrhages, ischemia), infectious, inflammatory, and autoimmune causes. Thus, it is germane to extensively search for the cause of the NCSE because the immediate and proper therapy of the underlying cause of, especially the acute symptomatic, forms of NCSE is at least as important as the antiictal treatment.
\end{abstract}

\section{Introduction}

Nonconvulsive status epilepticus (NCSE) poses a significant multidimensional challenge for emergency and intensive care physicians as well as neurologists [1,2]. This primarily starts with the diagnosis and related detection and confirmation of NCSE, and continues through optimal therapy and difficult prognosis [3]. Although a convulsive status epilepticus (CSE) needs only to be distinguished from a non-epileptic dissociative convulsive state, in the differential diagnostic spectrum and in appearance, NCSE can range from migraine, stroke, coma or delirium to psychiatric disease patterns such as stupor and psychosis [4,5]. Nowadays all paroxysmal focal (and sometimes even global) deficits are basically considered events suspicious of stroke, and therefore initially evaluated as such. While this may still be correct with respect to focal impairments such as paralysis or aphasia, focal impairments with temporary changes in - or loss of - consciousness occur only with considerable vertebrobasilar insufficiency of an ischemic nature, more frequently they are indicative of an epileptic, metabolic-toxic or migrainous origin. It should also be noted that a "plus" symptomology (movements, paresthesia, olfactory, visual, emotional, acoustic impressions) is predominantly present in epileptic seizures and status epilepticus, whereas in cases of stroke there is a "minus" symptomology (paralysis, hypesthesia, aphasia, amaurosis, etc.). The picture is obscured by the fact that "minus" symptoms can occur during epileptic episodes (paresis, aphasia, apraxia), while during strokes "plus" symptoms (hyperkinesia - limb-shaking TIAs, paresthesia, visual phenomena, etc.) may be observed.

The following presents the definition, various manifestations and types, classification, causes, epidemiology, brief pathophysiology as well as the diagnosis of NCSE.

\section{Definition}

It general it can be stated that NCSE is everything apart from CSE, but this is no real help. Shorvon formulated it more precisely: NCSE is a concept for a number of states in which electroencephalographic activity is present for an extended period, accompanied by nonconvulsive clinical symptoms [6]. Recently the Task Force of the International League Against Epilepsy (ILAE) published a comprehensive definition for the classification of status epilepticus:

"Status epilepticus is a condition resulting either from the failure of the mechanisms responsible for seizure termination or from the in- 
itiation of mechanisms, which lead to abnormally, prolonged seizures (after time point $\mathrm{t} 1$ ). It is a condition, which can have long-term consequences (after time point $\mathrm{t} 2$ ), including neuronal death, neuronal injury, and alteration of neuronal networks, depending on the type and duration of seizures" [7]. This definition includes 2 operational dimensions, that of time $t 1$, in which an epileptic attack can be considered to be clearly abnormally prolonged, and that of time $t 2$, from which, with continued epileptic seizure, can result in with serious temporary and/or irreversible subsequent damage within the nervous system or even within the entire organism (in the case of the CSE). It is clear that $\mathrm{t} 1$ and $\mathrm{t} 2$ are different for the various types of SE, and that this definition allows situation-related adaptation. Whereas $\mathrm{t} 1$ designates the time from which immediate treatment should start, $\mathrm{t} 2$ is the time of ongoing seizure activity after which there is a risk of long-term consequences [7]. Although this concept is on target, it stands or falls depending on the data reliability of $\mathrm{t} 1$ and $\mathrm{t} 2$. Here is where the difficulty begins. One the one hand, there are population-based studies in which the definitive duration of epileptic seizures or SE can often only be estimated and which tend to overestimate the duration of the seizure, since usually the postictal phase of the coma and the lack of response to external stimuli (being spoken to) are considered continuation of the seizure. Thus it can be seen that with elderly patients who generally suffer partial complex episodes with a somewhat longer reorientation phase, a particularly longer seizure time is "observed" $[8,9]$. In this population, only long-term video EEG monitoring (LVEM) could shed light on the actual duration of the seizure [10], but is seldom used [11]. On the other hand, studies of selected patient cohorts in which the duration of seizure could be determined exactly using LVEM demonstrated that $80 \%$ of epileptic attacks lasted less than $1 \mathrm{~min}$, and that $90 \%$ continued for less than 2 min [12-15]. Furthermore there are good indications that children's epileptic seizures can last significantly longer than those of adults [16]. Overall, however, Lowenstein's operational definition of 5 min seems justified for the CSE [17], as are the 10 min indicated by Young for focal NCSE [18], which the Task Force has now adopted for $\mathrm{t} 1$. In the absence of usable data, the authors of the Task Force decided, based on a form of generalized NCSE, absence status, a time of 10-15 min for $t 1$. It is even more difficult to determine the time 2 for the different types of SE because most of the results are based on animal experimental data and can hardly be transferred directly to a human model. The leading causes of SE in animal models do not occur in humans, and it remains unclear whether the time relationships in a rat, for example, an animal with a 2-year life expectancy can be applied unadapted to a human with an 80-year lifespan [19]. In concrete terms: if t2 lasts 20 min in a rat, is $\mathrm{t} 2$ still $20 \mathrm{~min}$ for humans or should it be multiplied by a factor of 40 or some intermediate value? Only few people are biopsied or autopsied after suffering SE. The few case reports and sole series [20] do not indicate exact duration of an SE to correlate histopathological changes with duration. Based on current knowledge, the Task Force decided to set this $\mathrm{t} 2$ for CSE at $30 \mathrm{~min}$, and in the case of focal NCSE, more than $60 \mathrm{~min}$. With respect to absence status, to date there are no clear indications that long duration is related to long-term damage.

\section{Types and Classification}

In 1962 at the first SE colloquium in Marseille, Gastaut noted that there are "so many types of SE as seizure types" [21]. This is true, since

in clinical practice hardly one NCSE resembles another. Nevertheless, a certain classification is possible. $>$ Fig. 1 illustrates a scheme based on the 2 dimensions of localization (focal vs. generalized) or consciousness (retained vs. limited). These scheme is also compatible with the new ILAE Task Force classification of NCSE. This classification is based on 4 axes, axis 1 being the semiology ( $\vee$ Table 1 ); axis 2 is the etiology ( $\triangleright$ Table 2 ); axis 3 is EEG correlates ( $\vee$ Table 3 ), and axis 4 is the age of the patient ( $\triangleright$ Table 4$)$. This concept takes account of the requirements for a classification supporting a clinical diagnosis, enabling research through standardization, while ensuring an individualized treatment concept for the patient. The matrix structure also allows for overlaps, e. g., in the case of the age-dependent SE forms (axis 4), which at the same time can also be semiological entities (axis 1 ) with partially specific etiology (axis 2) as well as EEG patterns (axis 3).

As a practical example, we present the example of the classification of NCSE of an adult with anti-NMDA receptor based limbic encephalitis:

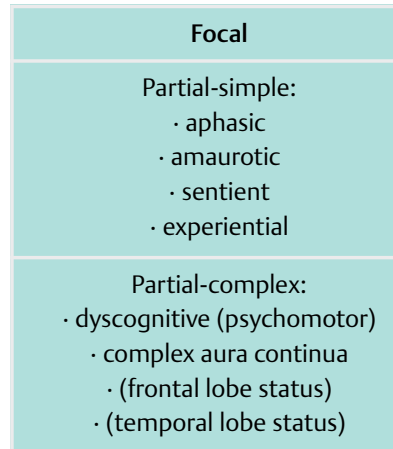

\section{Generalized}

nons

\begin{abstract}
- typical absence status - atypical absence status - de novo absence status (older patient; benzodiazepine abuse) - minimal myoclonic status with genetic generalized epilepsies
\end{abstract}

Status epilepticus in coma:

. "subtle" status epilepticus (after convulsive status)
· status epilepticus in critical illness status
- postanoxic (minimal myoclonic) status epilepticus

- Fig. 1 Graphical representation of types of nonconvulsive status epilepticus.

- Table 1 New ILAE classification of NCSE Axis 1 [7].

B-1: NCSE during coma, including so-called "subtle" status
B-2: NCSE without coma
B-2a: Generalized:
B-2aa: Typical absence status
B-2aa: Atypical absence status
B-2ac: Myoclonic absence status

B-2b: Focal:

B-2ba: Without impairment of consciousness (aura continua, with autonomic, sensory, visual, olfactory, gustatory, emotional/psychic/experiential, or auditory symptoms)

B-2bb: Aphasic status

B-2bc: With impaired consciousness

B-2c: Unclear whether focal or generalized

B-2ca: Autonomic SE 
- Table 2 New ILAE classification of NCSE Axis 2: Etiology [7].

A. Known cause:

- Acute:
- Remote:
- Progressive
- Status epilepticus in defined electroclinical syndromes
B. Unknown cause (formerly "cryptogenic")

- Table 3 New ILAE classification of NCSE Axis 3: EEG correlates [7].

\begin{tabular}{|c|c|c|}
\hline \multirow[t]{4}{*}{ A. } & \multirow[t]{4}{*}{ Location: } & $\begin{array}{l}\text { - generalized (including bilateral synchronous } \\
\text { patterns) }\end{array}$ \\
\hline & & - lateralized \\
\hline & & - bilateral independent \\
\hline & & - mutlifocal \\
\hline \multirow[t]{3}{*}{ B. } & \multirow{3}{*}{$\begin{array}{l}\text { Name of the } \\
\text { pattern: }\end{array}$} & - periodic discharges \\
\hline & & - rhythmic delta activity \\
\hline & & - spike-and-wave/sharp-and-wave plus subtypes \\
\hline \multirow[t]{4}{*}{ C. } & \multirow[t]{4}{*}{ Morphology: } & - steepness/sharpness of phases \\
\hline & & - number of phases (e.g., triphasic morphology) \\
\hline & & - absolute and relative amplitude \\
\hline & & - polarity (positive/negative) \\
\hline \multirow[t]{6}{*}{ D. } & \multirow{6}{*}{$\begin{array}{l}\text { Time-related } \\
\text { features: }\end{array}$} & - prevalence \\
\hline & & - frequency \\
\hline & & - duration \\
\hline & & - diurnal pattern duration and index \\
\hline & & - onset (sudden vs. gradual) \\
\hline & & - dynamics (evolving, fluctuating, or static) \\
\hline \multirow[t]{2}{*}{ E. } & \multirow[t]{2}{*}{ Modulation: } & - stimulus-induced \\
\hline & & - spontaneous \\
\hline \multirow[t]{2}{*}{ F. } & \multirow{2}{*}{$\begin{array}{l}\text { Effect of interven- } \\
\text { tion on the EEG: }\end{array}$} & - medication \\
\hline & & - stimulation \\
\hline
\end{tabular}

“predominant non-motor SE in an adult (axis 4) with limited consciousness (axis 1); EEG shows practically generalized rhythmic high-voltage delta activity as well as well as obscured high-frequency beta bursts (axis 3) due to acute (non-paraneoplastic, anti-NMDA receptor based) limbic encephalitis".

The types and semiology of the SE are determined by the localization of the focus and symptomatogenic zone. If motor areas involved, the SE is manifested as convulsive. If the affected zone is outside the motor areas, the SE is considered non-convulsive. The socalled "subtle" status epilepticus is a special case, that is, an SE that is initially convulsive, but changes to a nonconvulsive state. The section "Pathophysiology" will briefly describe this in more detail.

The following electroencephalographic clinical examples are presented as an illustration of classical NCSE:

- Inhibitory NCSE ( Fig. 2):

- Aphasic NCSE ( Fig. 3):
- Dyscognitive NCSE (- Fig. 4):

- Absence status ( $>$ Fig. 5):

- NCSE in metabolic coma ( $>$ Fig. 6): (cefepime)

- NCSE with structural lesion ( $\mathbf{F i g . ~ 7 ) : ~ ( t u m o r ) ~}$

- Postanoxic encephalopathy ( $>$ Fig. 8):

The concept of the NCSE encephalopathy continuum has been a very important finding in recent years regarding the classification of NCSE [22,23]. The authors postulate that the more responsive the EEG appears, and the closer it resembles a seizure pattern, the more likely it is that the patient's clinical condition is due to epileptic activity. This implies not only an actual epileptic diagnosis, but also promises that an immediate antiepileptic treatment will most likely improve the condition. Conversely, rigid, very regular (rhythmic or periodic), low-frequency ( $<2 \mathrm{~Hz}$ ) and non-responsive EEG patterns in a comatose patient do not seem to support either the diagnosis of NCSE or a response to intensive antiepileptic therapy. This concept takes into account the fact that often clinical situations are accompanied by an acute change in consciousness and/ or behavior along with epileptiform EEG changes, but there are reasonable doubts whether a true NCSE is present, but rather it might be suspected that the patient is in an encephalopathic or psychiatric state, and that the observed EEG changes reflect severely altered brain function. This gray area includes

- epileptic encephalopathy (such as appearing as a result of Dravet, Lennox-Gastaut syndromes or ring chromosome 20 syndrome)

- coma with static, non-developing EEG patterns (such as lateralized or generalized periodic discharges)

- behavioral issues in patients with epilepsy (such as related to psychosis)

- acute confusional states with epileptiform EEG discharges (such as during delirium).

Complicating the last 2 items are clear cases of "postictal" psychosis with continuous epileptic activity detected in deep electrode recordings [24, 25] as well as hypoactive delirium which can genuinely be of epileptic origin in the sense of NCSE.

In summary with respect to NCSE and concomitant coma, it should be noted that the better the responsiveness, and the more typical the EEG is (developing and declining epileptic activity), the better the treatability and prognosis are. Conversely, as a rule a non-responsive EEG and prominent structural brain damage are linked to an unfavorable prognosis [26, 27]. 
- Table 4 New ILAE classification of NCSE Axis 4: Age of actual occurrence [7].

A.

B.

C.

D.

E.

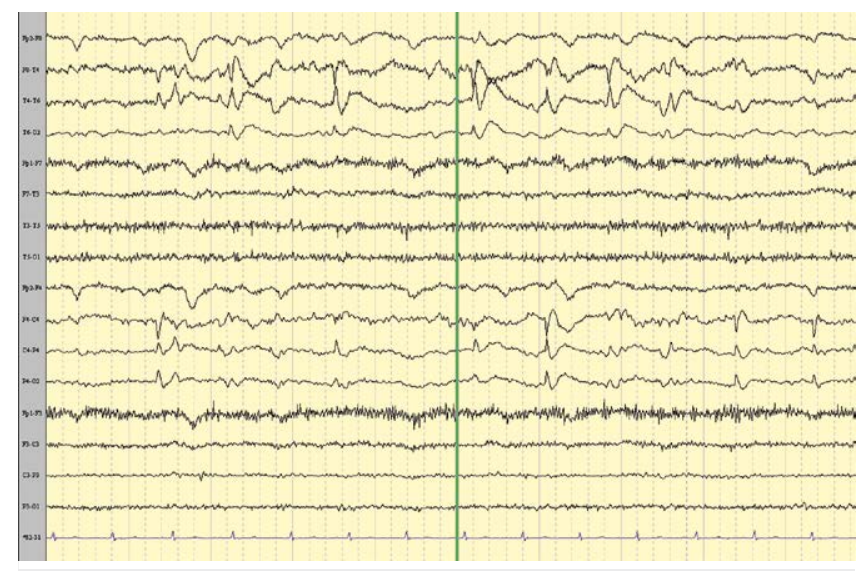

- Fig. 2 Inhibitory NCSE: 52-year-old female with a perfused right temporo-parieto-occipital malformation 3 years prior to the current event. She remained free of stroke after embolization. On day of admission referral with stroke alarm due to sudden left brachiofacial paralysis with full consciousness without previous tonic-clonic expression. An emergency MRI revealed neither reperfusion nor fresh ischemia. The EEG revealed continuous lateralized (pseudo) periodic discharges above the right temporal and central region. Symptoms ceased completely after IV administration of $5 \mathrm{mg}$ midazolam.

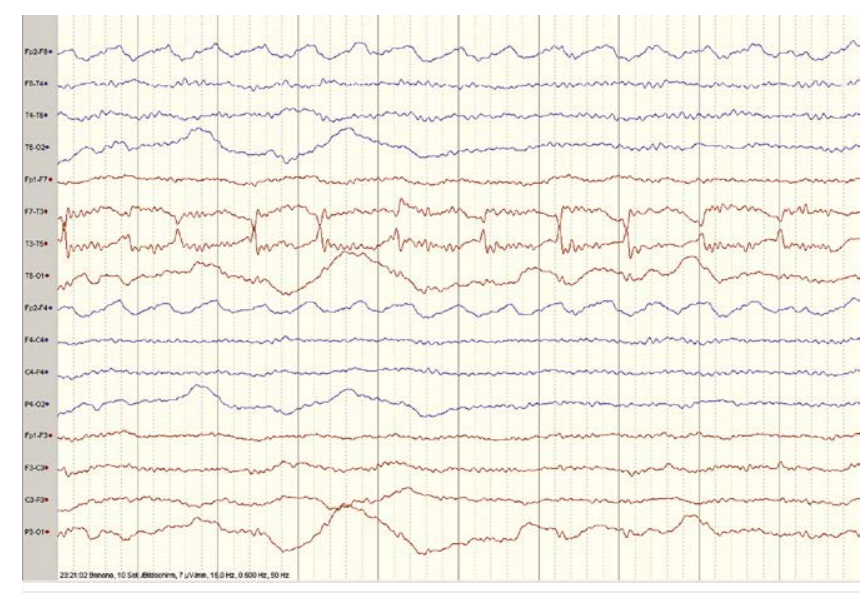

- Fig. 3 Aphasic NCSE: 84-year-old male with long history of arterial hypertension and depression. During an office visit to his personal physician, he suddenly could no longer speak, appeared very confused and apractic. Referral with stroke alarm. Determination of motor-stressed global aphasia and apraxia, but without paresis on the right side. In emergency MRI no hemorrhage or fresh ischemia. EEG revealed lateralized periodic discharges as left temporal sharp waves. Rapid disappearance of this activity after IV administration of $3 \mathrm{mg}$ midazolam; in typical manner full recovery from aphasia only after several days. 


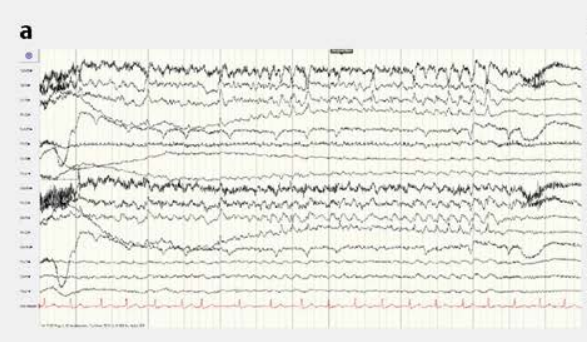

b

c

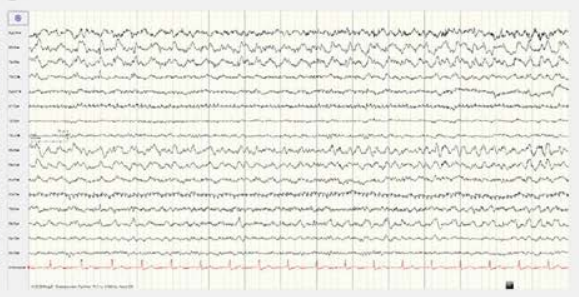

d
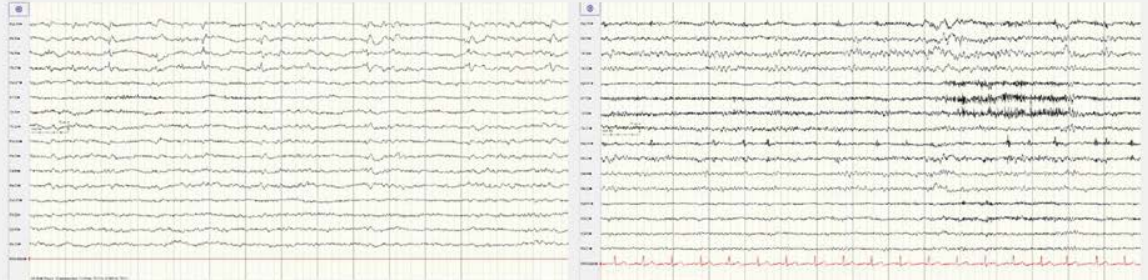

- Fig. 4 Dyscognitive NCSE: 69-year-old female patient with a decade of well-adjusted focal lesional epilepsy after extirpation of a right-side paraprepontine arachnoid cyst via temporary access. Increased confusion after a few days. Neighbor found patient in open doorway, wet and wandering around. She was disoriented in every dimension, constantly repeated that she didn't know what was going on. With structurally unchanged conditions but inflammatory CSF, the diagnosis of non-paraneoplastic limbic encephalitis could be made with clearly positive anti-GAD antibodies and negative onco PET. The EEG demonstrated practically continuous lateralized periodic discharges in the right hemisphere with slight sharp wave and spike wave morphology a. One day later, only lateralized, continuous periodic discharges appear with right temporal delta waves and sharp-wave morphology after continuous administration of low-dose midazolam via perfusor and IV levetiracetam as well as preexisting lacosamide and topiramate therapy $\mathbf{b}$. After initiation of intensive immunomodulation with high-dose methyl-prednisolone and IV immunoglobulins followed by rituximab, epileptic activity decreased significantly 10 days after the onset of the symptoms; there were still (pseudo-) periodical lateralized discharges seen in a clinical electroencephalographic borderland between status epilepticus and encephalopathy c. An additional 3 weeks later, only an intermittent mass with broad waves and right frontotemporal phase reversal can be seen $\mathbf{d}$. Clinically, the patient continued to suffer from marked memory loss as well as pronounced perseveration.

\section{Pathophysiology}

A detailed description of the pathophysiology of NCSE would go beyond the limits of this overview. Nevertheless the most significant pathophysiological basic concepts will be mentioned for 2 reasons. Firstly, as discussed above, the new definition and classification of SE by the selection of time points $t 1$ and $t 2$ clearly underlines the importance of pathophysiological processes. Secondly, the mechanisms of SE are important for understanding the treatment concepts mentioned in the rest of this article. Except for a few points (primarily the systemic consequences) the pathophysiology of NCSE differs little from that of CSE; therefore the following will mention SE.

It should be emphasized again that over $99.9 \%$ of all seizures cease by themselves; the brain thus has a variety of efficient mechanisms to halt seizures [28]. In the case of SE, what leads to a failure of this protection?

A definite imbalance of the inhibitory and excitatory influences at the molecular neuronal level is assumed. Receptor phenomena as well as critically increased energy consumption play an important role in this. If insufficient ATP is provided during SE, the ATPdependent sodium-potassium pump fails, and the increased extracellular potassium level results in over-excitability as well as pronounced acidosis [29]. If an epileptic attack persists, the inhibitively active gamma-amino-butyric acid (GABA) receptors, type $A$ $(G A B A(A) R)$ are increasingly altered in their pentameric composition, which unlike GABA itself, also makes agonists such as benzodiazepines increasingly more resistant. In addition, GABA(A) receptors are endocytosed in the synaptic cleft, and are reduced in their total number so that less inhibitory influences can also be effective there $[30,31]$. Simultaneously, sustained epileptic activity results in an endoplasmic synthesis of the exciting glutamatergic $\mathrm{N}$-methyl-D-aspartate (NMDA) as well as $\alpha$-amino-3-hydroxy-5-methyl-4-isoxazolepropionate (AMPA) receptors which maintains and prolongs synaptic over-excitement [32,33]. As a result, neurons and glial cells are flooded by glutamate, which can no longer buffer and regenerate the glial cells, whereupon the neurons die from acute excitotoxic cell death by an unbraked inflow of $\mathrm{Ca} 2+$ ions. Activation of AMPA receptors also leads to membrane dissolution, likewise with cell death. These processes, in turn, activate inflammatory processes (so-called inflammasome), leading to the opening of the blood-brain barrier, the invasion of defense cells and the production of cytokines and chemokines. While the latter lead to further inflammatory cells, the former, mainly interleukin-1 $\beta$ - interleukin-2 and 6 as well as tumor necrosis factor $\alpha$ greatly reduce the seizure threshold [34, 35]. In addition, the efflux of albumin through the open blood-brain barrier likewise promotes seizure [36]. It should be noted that in an individual patient the intensity of these reaction cascades is additionally genetically and epigenetically determined [37].

Nowadays, epilepsy and related seizures are not considered conditioned solely by these cellular mechanisms, but are increasingly understood as a network disorder. Therefore it should be assumed that in the development of an (NC)SE it is significant whether cell groups with important switching/linkage functions (so-called "hubs") are involved in the generation and propagation of an SE, 

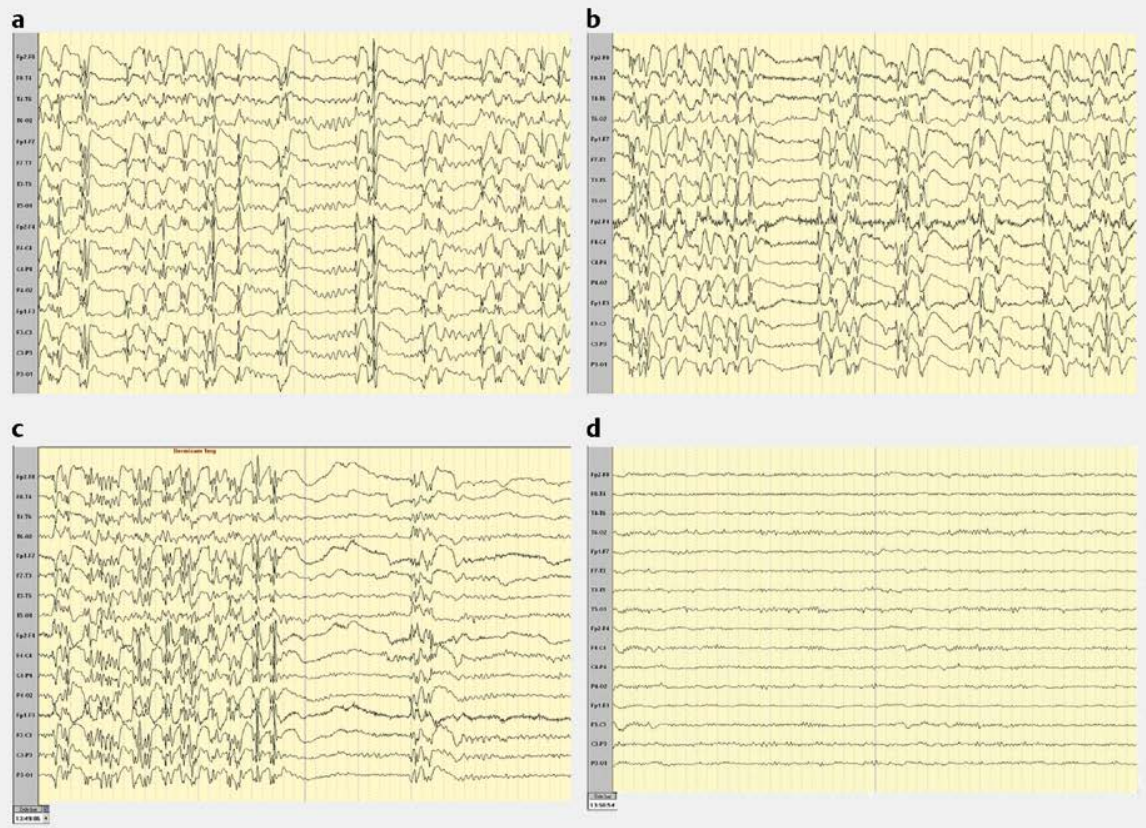

- Fig. 5 Absence status: 47-year-old male patient with tonic-clonic awakening episodes and absence since the age of 17. Incomplete control using valproate and primidone. After slight dosage increase of valproate, unanticipated almost fatal hyperammonemic encephalopathy. Therefore change to levetiracetam, topiramate and lamotrigine. There were several episodes of absence status, in which the patient wandered aimlessly, asked repetitive questions, "answered" questions, but did so like a "symptomatic epileptic" (and not a classic psychiatric case) Ganser syndrome response (e. g. date confusion: 16th November instead of 17th October). The EEG disclosed almost continuous generalized periodic discharges with (poly-) spike-wave morphology and a frequency between 2.5 and $4 \mathrm{~Hz}$ interrupted by short sections of normal alpha-basic activity a. After fractional administration of $8 \mathrm{mg}$ of lorazepam over $45 \mathrm{~min}$, there was no change in the image, except for a flattening and frequency increase (beta overlay) of the basic activity $\mathbf{b}$. After $1 \mathrm{mg}$ of midazolam c, epileptic activity completely disappeared within $90 \mathrm{~s} \mathbf{d}$, and the patient was reoriented within a few minutes.

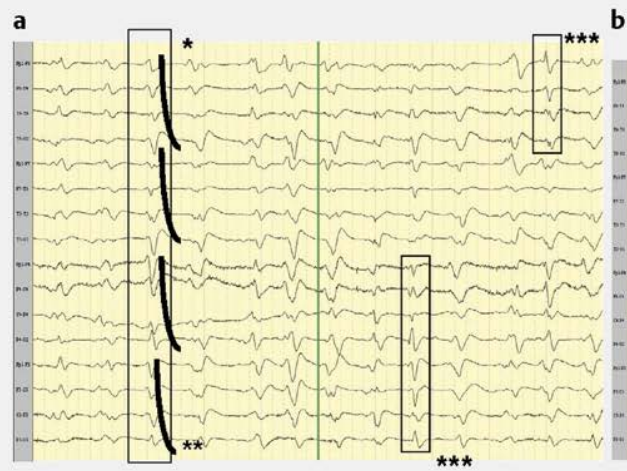

b

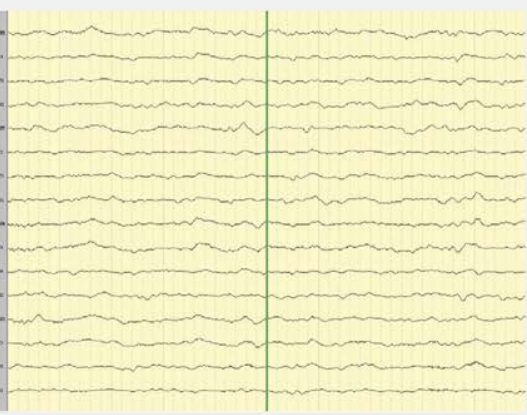

\begin{abstract}
- Fig. 6 NCSE in metabolic coma: 83-year-old male patient with E. coli sepsis after hip prosthesis implantation with multiple retroperitoneal abscesses. Treatment with rifampicin and cefepime. 2 days later, the patient became comatose in renal failure despite immediate initiation of hemodialysis. The EEG a showed generalized periodic discharges with triphasic morphology $\left({ }^{*}\right)$ and fronto-occipital shift $\left({ }^{* *}\right)$. In addition, bilaterally independent periodic discharges with sharp-slow-wave morphology were found ( ${ }^{* * *} /$ framing). After IV administration of $1 \mathrm{mg}$ of lorazepam $\mathbf{b}$, the bilaterally independent periodic as well as the generalized discharges with triphasic morphology disappeared.
\end{abstract}

since these lead to changes in the often distantly connected exciting and inhibiting networks. Likewise, complex systems such as the brain or individual regions of it can enter a state of increasing susceptibility or instability (criticality, such as triggering an avalanche [38]), in which frequently only an additional tiny impulse is needed to develop a disproportionately strong, destructive reaction.

Within the context of pathophysiology, the concept of the "subtle" SE, which corresponds in its appearance to NCSE, should also be mentioned. In animal experiments as well as in studies of humans with SE, Treiman and associates observed practically identical cascades of electroencephalographic-clinical phenomena. This shows a transition from initial typical dynamic EEG seizure patterns with clinically convulsive seizures over 5 stages towards a virtually non-responsive burst-suppression pattern with a clinically non-convulsive appearance [39]. The stopping of the clinically convulsive activity was initially explained with energetic exhaustion ("empty 


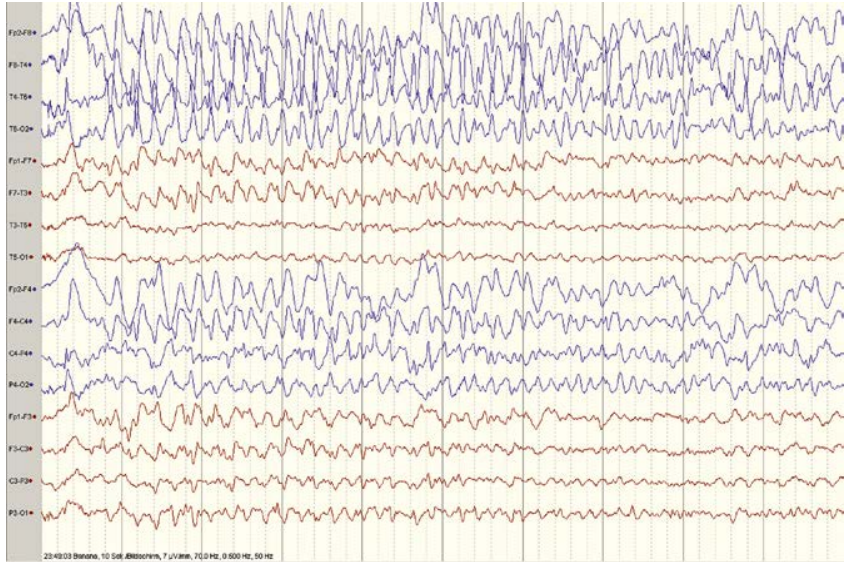

- Fig. 7 NCSE with structural lesion: 62-year-old female patient with right frontal meningioma removal 3 days previously. After unremarkable progress, the staff of the monitoring station noticed that the patient did not answer questions quickly, as she was otherwise precise and was "awkward" during the morning care. The EEG revealed a bone gap and periodic high-amplitude discharges with sharp-wave morphology above virtually the entire right anterior quadrant which abated only after days despite midazolam perfusion and IV valproate and levetiracetam.

batteries"), but this occurs among humans only after the most extreme physical stress. It was discovered later that cell groups in the substantia nigra and also the nucleus subthalamicus can block the motor pathways like a gate function during an SE without the SE ceasing, which leads to a clinical ("subtle") NCSE [28].

In addition to these immediate effects, SE in its convulsive form causes marked systemic effects [40], such as lactic acidosis, hypoxia, sympathetic stress including myocardial damage and rhabdomyolysis which can immediately become life-threatening and additionally directly result in the risk of neuronal damage, requiring urgent direct treatment. In animal experiments [41] and controversially in humans $[42,43]$ NCSE can likewise result in neuronal cell death [44-49], although these findings were obtained indirectly through observation of cognitive restrictions or permanent MRI changes after the NCSE. The sympathetic stress can also be significantly increased and cause autonomous symptoms (dysregulation, hyper-/hypotension, hyper-/hypoventilation, tachy-/bradyarrhythmia to asystole) [50], which together with the frequently life-threatening semiology likewise makes rapid vigorous treatment necessary.

\section{Causes}

In principle, the causes of NCSE are not significantly different from those that can trigger CSE. An important issue with regard to etiology is the question of whether the patient is known to suffer from epilepsy or not. If the patient is known to suffer from epilepsy, then changes in medication, in the widest sense, are the most important cause. This may result from a drop in the drug level due to a planned reduction or an attempt to gradually reduce antiepileptic therapy, or - more frequently - the patient attempts this on his own without consulting the treating physician or is non-compliant and takes medication irregularly. A drop in the effective concentration of antiepileptic drugs can also be caused by a supply gap (trav-

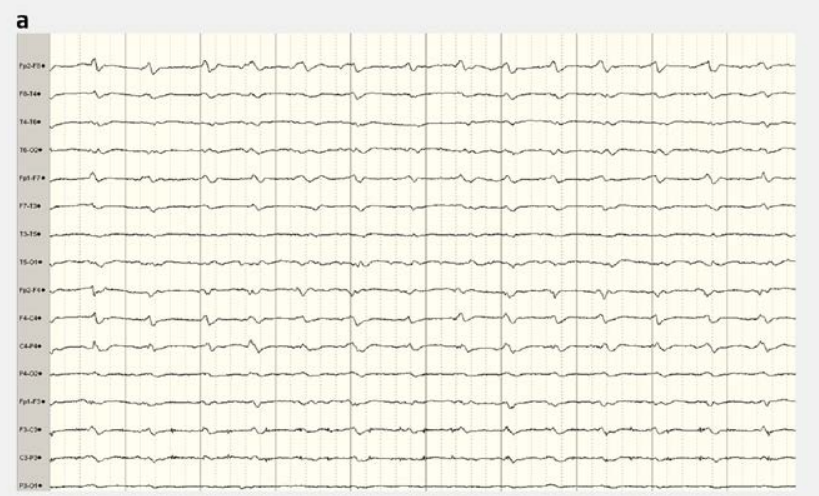

b

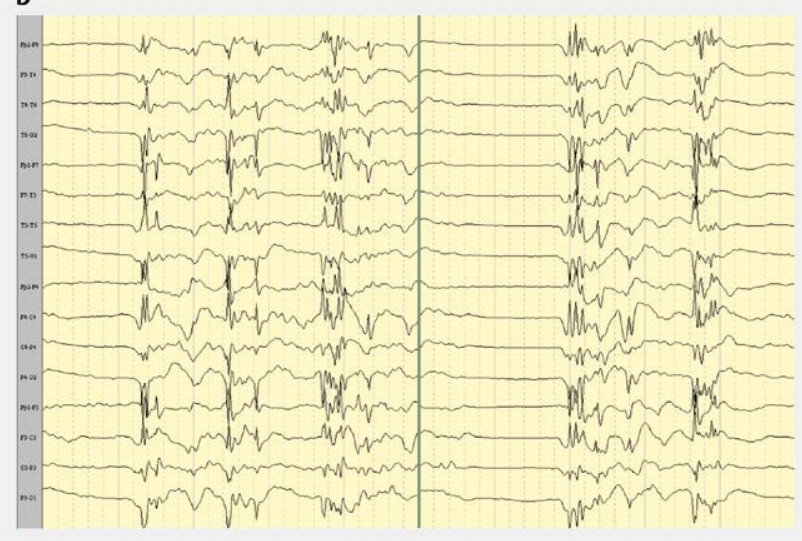

- Fig. 8 Postanoxic encephalopathy. a 70-year-old male patient after cardiopulmonary resuscitation (CPR) due to ventricular fibrillation with known severe $\mathrm{CHD}$. After $24 \mathrm{~h}$ hypothermia $\left(34^{\circ} \mathrm{C}\right)$ the patient remained comatose without sedation. $72 \mathrm{~h}$ after CPR the EEG indicated a curve nonresponsive to exterocepive stimuli with generalized periodic discharges with partial triphasic, partial sharp-wave morphology. b 53-year-old female patient with respiratory exhaustion at home and long resuscitation (hypoxia $35 \mathrm{~min}$ ). Treatment for hypothermia. After warming without sedatives, an image of a non-responsive burst-suppression curve with rhythmic discharges occurring in the bursts with spike-wave morphology, clinically appearing as generalized myclonia. The patient remained comatose and somato-sensory evoked median nerve potentials indicated no cortical-related stimulus response $72 \mathrm{~h}$ post-CPR.

el, car trouble, etc.). Less obvious reasons for a drop in effective medication level with subsequent development of SE can be the addition of an anti-inflammatory drug (e. g., gyrase inhibitor) or a strong enzyme inductor (rifampicin, carbamazepine, etc.) [51].

In the treatment of a genetically generalized epilepsy syndrome, absence or myoclonic status epilepticus can be precipitated by the use of an inappropriate antiepileptic medications such as carbamazepine/oxcarbazepine/phenytoin/tiagabine/vigabatrin/pregabalin/gabapentin [52]. Paradoxically, an overdose of any antiepileptic medication (apart from benzodiazepines and barbiturates) or highly-toxic levels can cause SE. Conversely, withdrawal of alcohol, benzodiazepines and barbiturates can trigger a generalized CSE. The "de novo" absence status of generally older patients after cessation of long-term consumption of benzodiazepines (in the form of sleeping pills) represents an outlier [53]. 
- Table 5 Causes of NCSE.

- Unknown, "cryptogenic"

- "symptomatic":

- Intracerebral lesions:

- Ischemic microangiopathy

- Alzheimer's disease

- Tumors (low grade > higher grade > metastases >lymphoma > meningeosis)

- Intracranial hemorrhage (intracerebral lobar hemorrhage > subarachnoid hemorrhage > subdural hematoma > epidural hematoma)

- Ischemic stroke (territorial > lacunar infarction)

- Sinus vein thrombosis

- Hydrocephalus occlusivus

- Posterior reversible encephalopathy syndrome (PRES)

- Eclampsia

- Infections:

- Autoimmune diseases

- Antineuronal antibody limbic encephalitis (paraneoplastic or non-paraneoplastic)

- Systemic lupus erythematosus

- Multiple sclerosis

- Steroid-responsive encephalopathy with associated autoimmune thyroiditis (SREAT)

- Sprue/celiac disease

- Vasculitis

- Sarcoidosis

- Infections

- Cysticercosis

- Herpes simplex encephalitis

- HHV-6 encephalitis with immune suppression

- Abscesses

- Empyema

- Toxoplasmosis

- HIV encephalopathy

- Cryptococcosis

- Tuberculosis

- Pneumo-, strepto-, meningio- and staphylococcal meningitis

- Creutzfeldt-Jacob disease

- Metabolic-toxic

- Mitochondriopathy (MELAS, MERRF, PCD19)

- Porphyria

- Medication ( $>$ Table 6 )

- Drugs:

- Stimulants (amphetamines and derivates, designer drugs)

- Cocaine

- High-dosage opiates (including IV heroin)

- Poison

- Nerve gas (Sarin XV, etc.)

- Domoic acid

- Bicuculline

- Muscimol

- Pentylenetetrazol

- Electrolyte imbalance

- Hyponatremia

- Hypomagnesemia

- (Hypocalcemia)

- Sepsis

- Hormonal

- Hypoglycemia

- Hyperthyroidism

- Postanoxic

Obviously many epilepsy syndromes, even those starting in childhood, are frequently associated with (nonconvulsive) SE. This particularly applies to Dravet syndrome, SE syndrome with focal seizures, ring chromosome 20 and Lennox-Gastaut syndromes, mitochondriopathy, neuroceroid lipofuscinosis, etc.
In a narrow majority of cases, SE occurs in patients without known epilepsy, usually symptomatically in the course of developing or acute diseases, ingestion of medications which lower the seizure threshold, or drugs, or exposure to toxins. These causes are shown in > Table 5. 
- Table 6 Primary appearance characteristics of NCSE (according to [64]).

- Altered state of consciousness:

$82 \%$ of which:

- Confusion $49 \%$

- Coma $22 \%$

- Lethargy/apathy

- Memory impairment/loss

$21 \%$

- Speech impairment

- Myoclonia

- Disturbed behavior

- Anxiety, restlessness or delirium

- Extrapyramidal signs

- Hallucinations
$8 \%$

$15 \%$

$13 \%$

$11 \%$

$8 \%$

$7 \%$

$6 \%$

plained loss of consciousness demonstrated NCSE [70]; in a more recent study out of Vancouver, this proportion was reduced to $9.3 \%$ [71], and $8 \%$ of comatose patients at an intensive care unit in Richmond demonstrated NCSE [72]. A recent study showed that not only the availability of EEG as such, but also continuous monitoring of persons with loss of consciousness in the ICU not only significantly increased NCSE detection, but doubled the detection rate [10].

\section{Diagnosis}

The previous finding leads directly to the diagnosis of NCSE. It should be emphasized that diagnosis is based both on clinical observation of the patient and the resulting general suspicion of the presence of NCSE, but this almost always requires an EEG for absolute confirmation. The only exception to this rule is the situation usually in an emergency - during which no EEG is immediately available, and the patient, after administration of a test dose of a benzodiazepine, immediately recovers consciousness, that is, has a paradoxical reaction to the medication, and becomes more alert and reoriented.

The primary signs and symptoms of NCSE include an altered state of consciousness as well as speech impairment; $>$ Table 6 summarizes the frequency of these phenomena.

It has proved useful to go through the following basic symptom categories when NCSE is suspected:

- mental state

- behavior

- movement/impairment

- higher cortical functions

- autonomous signs

An initial typological classification of the NCSE can be made once the above have been carefully noted. $>$ Table 7 summarizes this information based on current reviews [5,73].

If, due to clinical observations, NCSE can be reasonably suspected, it must be confirmed with an EEG [70]. In general, the conditions apply to all other status epileptici: either epileptic activity can be seen continuously or there is a sequence of epileptic seizures between which the patient does not return to his prior condition. An initial frequently-used classification of EEG patterns in NCSE was presented by Young in 1996 [18], which was refined by Kaplan in 2007 [74]. In 2014 Beniczky et al. developed "general” terminology and criteria for EEG findings of NCSE (so-called "Salzburg criteria”) [75]. The 3 classifications are clearly compared in > Table 8. At the same time, Sutter and Kaplan published a clinically very valuable encyclopedic collection and overview of the EEG patterns of the different types of NCES [76].

The likely most important and clearest step toward standardization of EEG diagnostics is the nomenclature of the American Clinical Neurophysiology Society (ACNS) for the wave forms and patterns appearing in the EEG recordings of intensive care patients with change of consciousness [77]. Consistent use of these concepts supports not only comparative studies for research purposes, but also allows a broad understanding and reliable transfer of written EEG findings among different hospitals which can be essential for referrals. The structure and core concepts of the classification are briefly summarized in $>$ Table 9 . Basically, first localization 


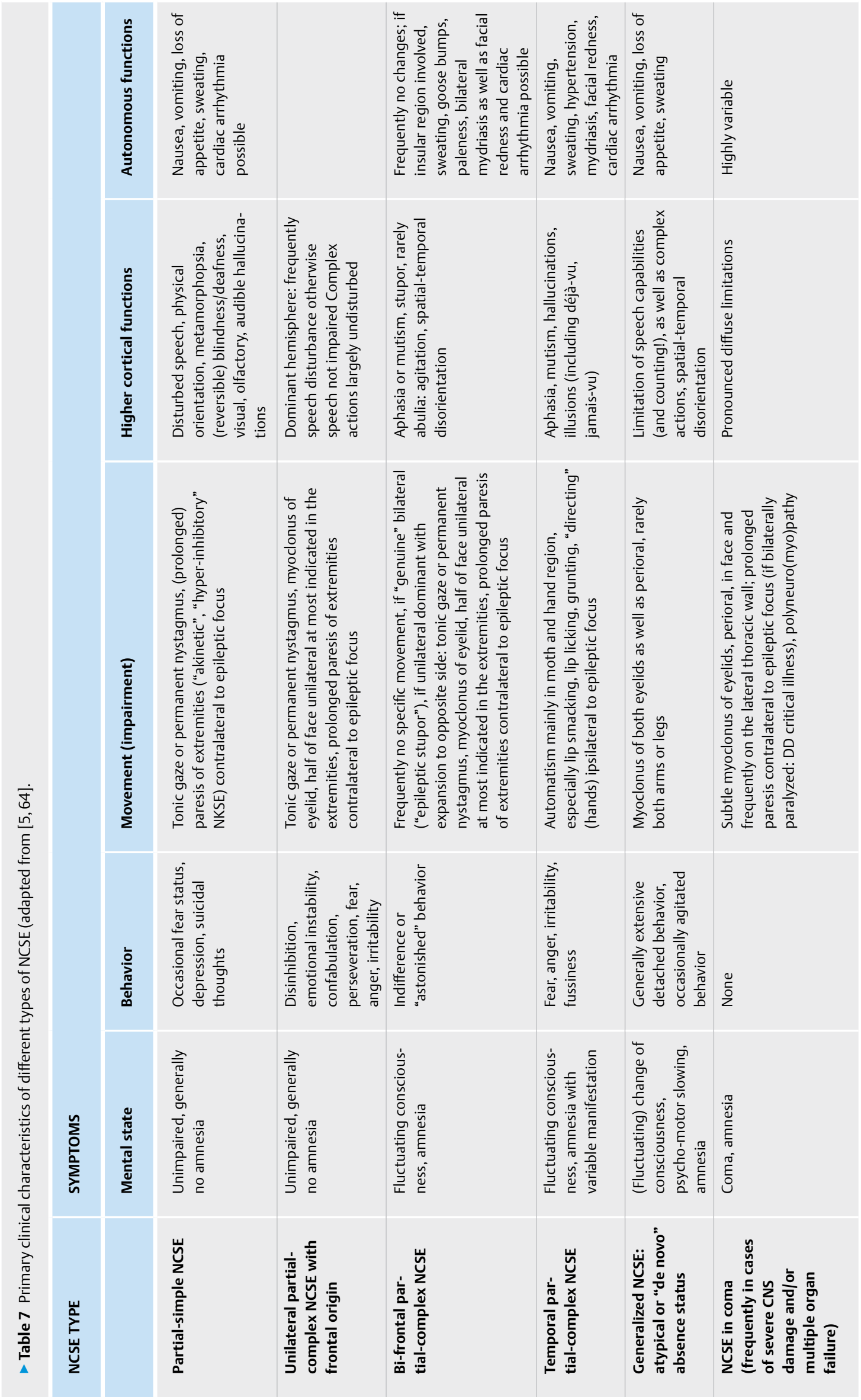


- Table 8 Summary of criteria for NKSE EEG patterns according to [64-66].

\section{Young}

\section{Primary Criteria:}

1. Repetitive generalized or focal spikes, sharp waves, spike-and-wave or sharp-and-slow wave complexes with a frequency $>3 \mathrm{~Hz}$

2. Repetitive generalized or focal spikes, sharp waves, spike-and-wave or sharp-and-slow wave complexes with a frequency $<3 \mathrm{~Hz}$ AND secondary criterion \#4

3. Sequential rhythmic waves and secondary criteria \#1, 2 AND 3 with or without \#4

Secondary criteria

1. "Increasing" onset: increase in amplitude and/or increased/decreased frequency

2. “Disappearing" end: decrease in amplitude or frequency

3. "Attenuation": curve flattening and/or slowing after end of discharge

4. Significant improvement of clinical status or EEG after administration of anticonvulsants

\section{Kaplan}

\section{In patients WITHOUT known epileptic}

encephalopathy:

1. Repetitive generalized or focal spikes, polyspikes, sharp waves, spike-and-waves or sharp-and-slow wave complexes with a frequency $>2.5 \mathrm{~Hz}$

2. Like 1) with discharges $<2.5 \mathrm{~Hz}$ with improvement in EEG as well as clinical status after prompt administration of anticonvulsants, generally benzodiazepines. Patient and EEG have to be tested for reactivity. EEG has to be reactive and baseline activity must resume.

3. Like 1) with discharges $<2.5 \mathrm{~Hz}$ but with focal ictal manifestations (facial myoclonia, glance deviation, nystagmus, myoclonia on the trunk or extremities)

4. Rhythmic waves (theta or delta) with frequency $>0.5 \mathrm{~Hz}$ with:

a) developing onset: increase in amplitude and/ or increased/decreased frequency

b) changing dynamics (frequency increase/ decrease) $(>1 \mathrm{~Hz}$ ) or location, (changes in amplitude) or morphology insufficient

c) Decrease in amplitude or frequency toward the end

d) Post-ictal periodic discharges, slowed baseline activity or attenuation

a), b) and c) can be caused to vanish via IV

benzodiazepine

In patients WITH known epileptic encephalopathy:

1. Frequent or continuous generalized spike-wave discharges tending toward propagation or frequency increase/decrease compared to an initial EEG with clearly observable change of clinical status

2. Decrease (improvement) of clinical and EEG parameters after administration of IV benzodiazepines

\section{Beniczky}

In patients WITHOUT known epileptic encephalopathy:

1. Epileptic discharges in a frequency of $>2.5 \mathrm{~Hz}$ or Epileptic discharges in a frequency of $<2.5 \mathrm{~Hz}$ or rhythmic theta-delta activity ( $>0.5 \mathrm{HZ}$ ) AND one of the following criteria:

a) clinical and EEG-verified improvement after administration of IV antiepileptic medication (benzodiazepines) or

b) subtle clinical ictal phenomena during the EEG recordings described above

c) Typical spatial-temporal development (essentially these correspond to Kaplan's item 4, however frequency must be $>1 \mathrm{~Hz}$ )

In patients WITH known epileptic encephalopathy:

1. Strongly prominent phenomena described above increasing in frequency, when compared to the initial EEG and additionally with clearly observable improvement of the clinical status

2. Clinical and EEG-verified after IV administration of anticonvulsants, especially benzodiazepines is mentioned, then the temporal form of the discharges. These 2 details can then be provided with additional indicators (so-called "modifiers") as required. Finally, there is also information on both the quantity of observed changes in relation to the basic activity as well as the basic activity itself.

In the acute phase, the EEG is the only reliable diagnostic method for determining or confirming NCSE. If an EEG is not available (e. g., in a smaller hospital or outside the recording times), a perfusion CT could be performed [78]. In the case of neurological failure symptoms this would, in the event of paresis, ideally show perfusion failure or weakening with an epileptic genesis, classically hyperperfusion should be present. However, in the case of a postictal neurological function deficit (in the sense of Todd's paralysis), hypoperfusion is likewise evident with this method. Assuming an ischemic event, this could be misinterpreted as a stroke even though an epileptic seizure or NCSE was originally present [79]. Presumably in such a "stroke-mimic" not a few patients receive an intravenous thrombolysis. Fortunately few side effects can be expected if the NCSE is treated with IVT [80].
Additional diagnostic modalities in special cases include MRI as well as SPECT and PET. The logistically complex SPECT provides the same information as a CT perfusion and is therefore hardly used anymore in the diagnostic evaluation of NCSE. The more elaborate PET provides information similar to SPECT and perfusion $C T$, but does not measure the blood flow, but rather the metabolism of the brain regions. While hypometabolism occurs in a stroke, hypermetabolism is evident during NCSE. Again, the same limitation applies to the equivocal assessment of hypometabolism as an expression of a postictal condition vs. ischemia.

It is interesting to note that typical changes are observed in the MRI of NCSE in diffusion-weighted imaging (DWI) sequences. In the region of the primary activity of a cortical status epilepticus a garland-shaped edema can be seen ( $\triangleright$ Fig. 9), in the hippocampus and presumably in the putamen and nucleus caudatus there is generally a point-like to diffuse cytotoxic edema such as is also present during ischemic strokes. While these changes are usually visible in the latter for approximately 3-6 weeks, the DWI changes disappear in the NCSE within a few days after its cessation [81-87]. 


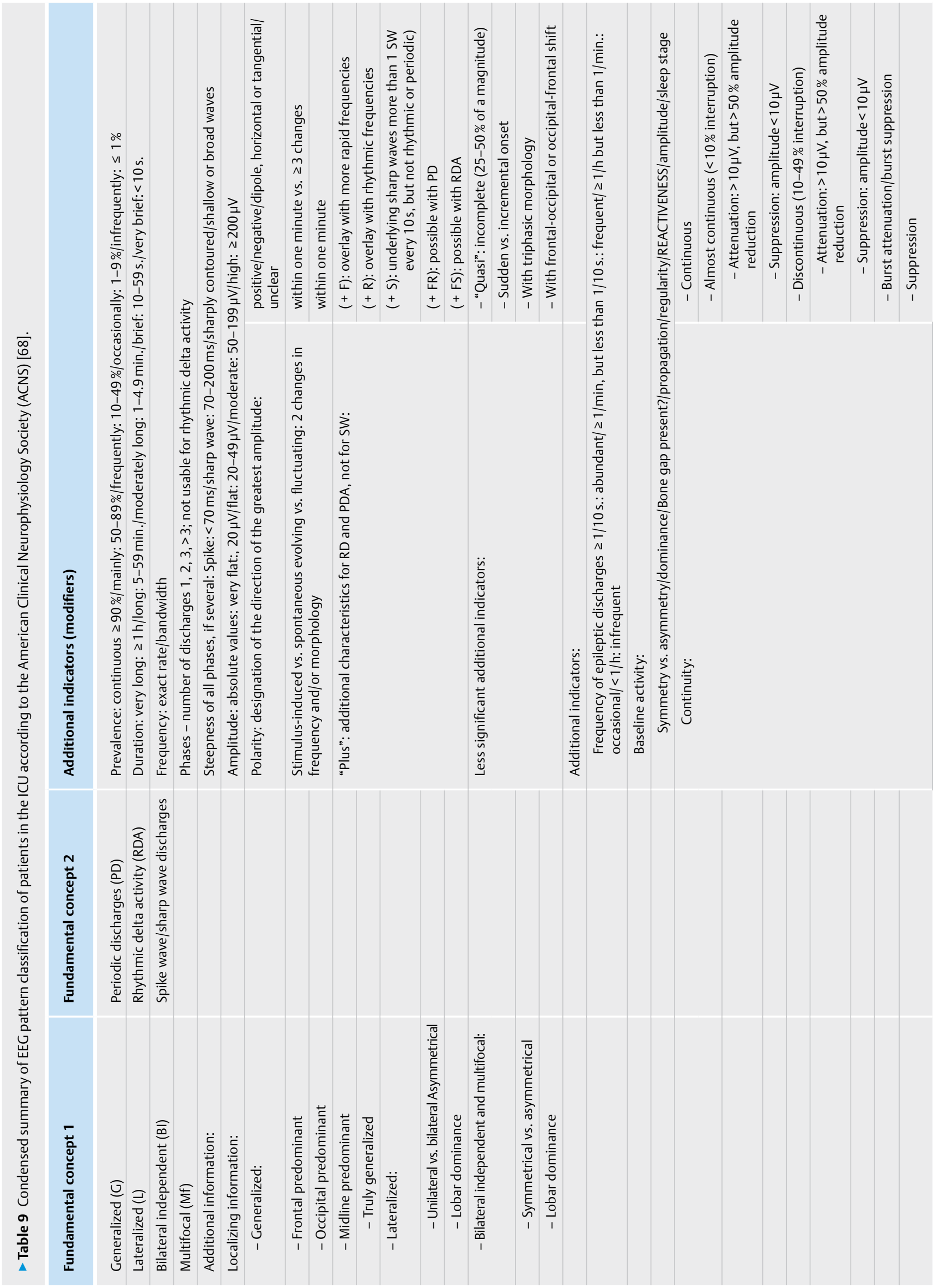




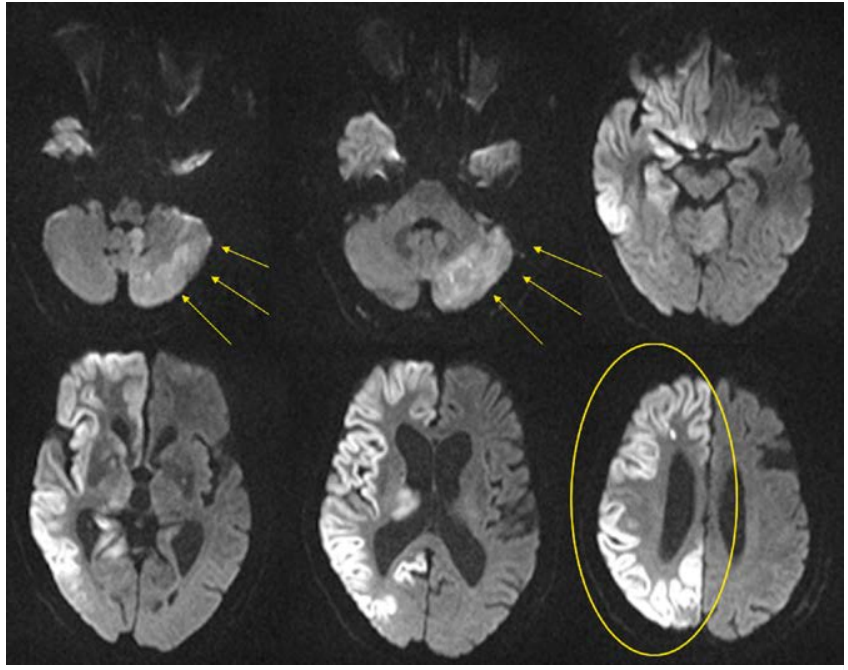

- Fig. 9 DWI changes during NCSE in a female patient with known epilepsy and severe sepsis as well as prior antiepileptic medication discontinued due to sepsis. DWI hyperintensities and related reduced diffusion in the ADC maps in the right hemisphere include the thalamus, hippocampus, the head of the nucleus caudatus, and parts of the occipital lobe, along with a marked swelling of the cortex of the affected areas. This DWI distribution pattern rules out cerebral ischemia, in particular since the vessels of the circle of Willis are all normal. Contralateral to the right-hemispherical cortical and subcortical abnormalities, DWI hyperintensities and reduced ADC maps were also found in the left cerebellar hemisphere, although they were less pronounced, but indicated an additional cerebral phenomenon, namely diaschisis.

\section{Conclusions}

NCSE is often "hidden", with unspecific symptoms, especially in emergency and intensive care units, where is it usually important to consider NCSE as the cause of observed signs and symptoms. In this context, the lower frequency of NCSE observed in general epidemiological studies compared to CSE may be explained by the fact that CSE cannot be overlooked, whereas this is unfortunately still the case with respect to NCSE. Pathophysiologically the same mechanisms are at work in both CSE and NCSE, but the systemic sequelae are less prominent in NCSE, but can also be fatal as the result of autonomous cardiopulmonary effects. Electroencephalography plays a central diagnostic role, since using this modality can NCSE be diagnosed with certainty.

\section{Conflict of interest}

The author declare no conflicts of interest.

\section{References}

[1] Maganti R, Gerber P, Drees C et al. Nonconvulsive status epilepticus. Epilepsy Behav 2008; 12: 572-586

[2] Rosenow F, Knake S, Hamer HM. Nonkonvulsiver Status epilepticus. Modeerscheinung oder behandlungspflichtige Realität? Nervenarzt 2012; 83: 1551-1558
[3] Fernández-Torre JL, Kaplan PW, Hernández-Hernández MA. New understanding of nonconvulsive status epilepticus in adults: treatments and challenges. Expert Rev Neurother 2015; 15: 1455-1473

[4] Beleza P, Rocha J, Pinho J. Diagnosis, etiology, and treatment of nonconvulsive status epilepticus, a semiological oriented review. Neurologist 2015; 19: 160-167

[5] Sutter R, Semmlack S, Kaplan PW. Nonconvulsive status epilepticus in adults - insights into the invisible. Nat Rev Neurol 2016, [epub ahead of print] April 11 doi:10.1038/nrneurol.2016.45

[6] Shorvon S. What is nonconvulsive status epilepticus, and what are its subtypes? Epilepsia 2007; 48 (Suppl 8): S35-\$38

[7] Trinka E, Cock H, Hesdorffer D et al. A definition and classification of status epilepticus - report of the ILAE Task force on Classification of Status Epilepticus. Epilepsia 2015; 56: 1515-1523

[8] Sung CY, Chu NS. Status epilepticus in the elderly: etiology, seizures type, and outcome. Acta Neurol Scand 1989; 80: 51-56

[9] Cheng S. Non-convulsive status epilepticus in the elderly. Epileptic Disord 2014; 16: 385-394

[10] Sutter R, Fuhr P, Grize L et al. Continuous video-EEG monitoring increases detection rate of nonconvulsive status epilepticus in the ICU. Epilepsia 2011; 52: 453-457

[11] Naeije G, Depondt C, Meeus C et al. EEG patterns compatible with nonconvulsive status epilepticus are common in elderly patients with delirium: a prospective study with continuous EEG monitoring. Epilepsy Behav 2014; 36: 18-21

[12] Theodore WH, Porter RJ, Perry JK. Complex partial seizures: Clinical characteristics and differential diagnosis. Neurology 1983; 33 : 1115-1121

[13] Theodore WH, Porter RJ, Albert P et al. The secondarily generalized tonic-clonic seizure: A videotape analysis. Neurology 1994; 44: 1403-1407

[14] Jenssen S, Gracely EJ, Sperling MR. How long do most seizures last? A systematic comparison of seizures recorded in the epilepsy monitoring unit. Epilepsia 2006; 47: 1499-1503

[15] Afra P, Jouny CC, Bergey GK. Duration of complex partial seizures: Intracranial EEG study. Epilepsia 2008; 49: 677-684

[16] Shinnar S, Berg AT, Moshé SL et al. How long do new-onset seizures in children last? Ann Neurol 2001; 49: 659-664

[17] Lowenstein DH, Bleck T, Macdonald RL. It's time to revise the definition of status epilepticus. Epilepsia 1999; 40: 120-122

[18] Young GB, Jordan KG, Doig GS. An assessment of nonconvulsive seizures in the intensive care unit using continuous EEG monitoring: An investigation of variables associated with mortality. Neurology 1996; 47: 83-89

[19] Sloviter RS, Zappone CA, Bumanglag AV et al. On the relevance of prolonged convulsive status epilepticus in animals to the etiology and neurobiology of human temporal lobe epilepsy. Epilepsia 2007; 48 (Suppl 8): S6-S10 Erratum in: Epilepsia 2007; 482382

[20] Corsellis JA, Bruton C]. Neuropathology of status epilepticus in humans. Adv Neurol 1983; 34: 129-139

[21] Gastaut H. A propos d'une classification symptomatologique des états de mal épileptiques. In: Gastaut H, Roger J, Loeb H.eds. Les états de mal épileptiques. Paris: Masson; 1967: 1-8

[22] Chong DJ, Hirsch LJ, Which EEG. patterns warrant treatment in the critically ill? Reviewing the evidence for treatment of periodic epileptiform discharges and related patterns. J Clin Neurophysiol 2005; 22: 79-91

[23] Bauer G, Trinka E. Nonconvulsive status epilepticus and coma. Epielpsia 2010; 51: 177-190

[24] Seeck M, Alberque C, Spinelli L et al. Left temporal rhythmic electrical activity: A correlate for psychosis? A case report. J Neural Transm 1999; 106: 787-794 
[25] Kuba R, Brázdil M, Rektor I. Postictal psychosis and its electrophysiological correlates in invasive EEG: A case report study and literature reveiw. Epilepsy Behav 2012; 23: 426-430

[26] Sutter R, Kaplan PW, Valença M et al. EEG for diagnosis and prognosis of acute nonhypoxic encephalopathy: History and current evidence. J Clin Neurophysiol 2015; 32: 456-464

[27] Sutter R, Kaplan PW. Clinical, electroencephalographic, and neuroradiological outcome predictors in acute nonhypoxic encephalopathy: A nine-year cohort study. Clin EEG Neurosci 2016; 47: 61-68

[28] Lado FA, Moshé SL. How do seizures stop? Epilepsia 2008; 49: 1651-1664

[29] Meldrum BS. Concept of activity-induced cell death in epilepsy: Historical and contemporary perspectives. Prog Brain Res 2002; 135: 3-11

[30] Naylor DE, Liu H, Wasterlain CG. Trafficking of GABA(A) receptors, loss of inhibition, and a mechanism for pharmacoresistance in status epilepticus. J Neurosci 2005; 25: 7724-7733

[31] Goodkin HP, Joshi S, Mitchedlishvili Z et al. Subunit-specific trafficking of GABA(A) receptors during status epilepticus. J Neurosci 2008; 28: $2527-2538$

[32] Hunt DL, Castillo PE. Synaptic plasticity of NMDA receptros: Mechanisms and functional implications. Curr Opin Neurobiol 2012; 22: 496-508

[33] Naylor DE, Liu H, Niquet J et al. Rapid surface accumulation of NMDA receptors increases glutamatergic excitation during status epilepticus. Neurobiol Dis 2013; 54: 225-238

[34] Holzer F], Seeck M, Korff CM. Autoimmunity and inflammation in status epilepticus: from concepts to therapies. Expert Rev Neurother 2014; 14: 1181-1202

[35] Vezzani A, Dingledine R, Rossetti AO. Immunity and inflammation in status epilepticus and its sequelae possibilities for therapeutic application. Expert Rev Neurother 2015; 15: 1081-1092

[36] Fabene PF, Navarro Mora G, Martinello M et al. A role for leukocyte-endothelial adhesion mechanisms in epilepsy. Nat Med 2008; 14 : 1377-1383

[37] Henshall DC. MicroRNAs in the pathophysiology and treatment of status epilepticus. Front Mol Neurosci 2013; 6: 37 doi:10.3389/ fnmol.2013.00037

[38] Worrell GA, Cranstoun SD, Echauz J et al. Evidence of self-organized criticality in human epileptic hippocampus. Neuroreport 2002; 13 : 2017-2021

[39] Treiman DM, Walton NY, Kendrick C. A progressive sequence of electroencephalographic changes during generalized convulsive status epilepticus. Epilepsy Res 1990; 5: 49-60

[40] Shorvon S. the management of status epilepticus. J Neurol Neurosurg Psychiatry 2001; 70 (Suppl2): II22-1I27

[41] Sloviter RS. Decreased hippocampal inhibition and a selective loss of interneurons in experimental epilepsy. Science 1987; 235: 73-76

[42] Young GB, Jordan KG. Do nonconvulsive seizures damage the brain? - Yes. Arch Neurol 1998; 55: 117-119

[43] Aminoff M]. Do nonconvulsive seizures damage the brain? - No. Arch Neurol 1998; 55: 119-120

[44] Wasterlain CG, Fujikawa DG, Penix L et al. Pathopyhsiological mechanisms of brain damage from status epilepticus. Epilepsia 1993; 34 (Suppl 1): S37-S53

[45] Krumholz A, Sung GY, Fisher RS et al. Complex partial status epilepticus accompanied by serious morbidity and mortality. Neurology 1995; 45: 1499-1504

[46] Fujikawa DG, Itabashi HH, Wu A et al. Status epilepticus-induced neuronal loss in humans without systemic complications of epilepsy. Epilepsia 2000; 41: 981-991
[47] Parmar H, Lim SH, Tan NCK et al. Acute symptomatic seizures and hippocampus damage: DWI and MRS findings. Neurology 2006; 66: 1732-1735

[48] Bauer G, Gotwald T, Dobesberger J et al. Transient and permanent magnetic resonance imaging abnormalities after complex partial status epilepticus. Epilepsy Behav 2006; 8: 666-671

[49] Vespa PM, McArthur DLXu Y et al. Nonconvulsive seizures after traumatic brain injury are associated with hippocampal atrophy. Neurology 2010; 75: 792-798

[50] van der Lende M, Surges R, Sander JW et al. Cardiac arrhythmias during after epileptic seizures. J Neurol Neurosurg Psychiatry 2016; 87: 69-74

[51] Sutter R, Rüegg S, Tschudin-Sutter S. Seizures as adverse events of antibiotic drugs: a systematic review. Neurology 2015; 85: 1332-1341

[52] Thomas P, Valton L, Genton P. Absence and myoclonic status epilepticus.precipitated by antiepileptic drugs in idiopathic generalized epilepsy. Brain 2006; 129: 1281-1292

[53] Thomas P, Beaumanoir A, Genton P et al. "de novo" absence status of late onset: report of 11 cases. Neurology 1992; 42: 104-110

[54] Pandis D, Scarmeas N. Seizures in Alzheimerdisease: clinical and epidemiological data. Epilepsy Curr 2012; 12: 184-187

[55] Nicastro N, Assal F, Seeck M. From here to epilepsy: The risk of seizure in patients with Alzheimer's disease. Epileptic Disord 2016; 16: 1-12

[56] Amatniek JC, Hauser WA, DelCastillo-Castaneda C et al. Incidence and predictors of seizures in patients with Alzheimer's disease. Epilepsia 2006; 47: 867-872

[57] Scarmeas N, Honig LS, Choi H et al. Seizures in Alzheimer's disease: Who, when, and how common? Arch Neurol 2009; 66: 992-997

[58] Irizarry MC, Jin S, He F et al. Incidence of new-onset seizures in mild to moderate Alzheimer disease. Arch Neurol 2012; 69: 368-372

[59] Sherzai D, Losey T, Vega $S$ et al. Seizures and dementia in the elderly: Nationwide inpatient sample 1999-2008. Epilepsy Behav 2014; 36: 53-56

[60] Beyenburg S, Elger CE, Reuber M. Acute confusion or altered mental state: Consider nonconvulsive status epilepticus. Gerontology 2007; 53: 388-396

[61] Noebels J. A perfect storm: Converging paths of epilepsy and Alzheimer's dementia intersect in the hippocampal formation. Epilepsia 2011; 52 (Suppl 1): S39-S46

[62] Feddersen B, Rémi J, Einheilig M et al. Parkinson's disease: Less epileptic seizures, more status epilepticus. Epilepsy Res 2014; 108: 349-354

[63] DeLorenzo RJ, Hauser WA, Towne AR et al. A prospective, population-based epidemiologic study of status epilepticus in Richmond, Virginia. Neurology 1996; 46: 1029-1035

[64] Hesdorffer DC, Logroscino G, Cascino G et al. Incidence of status epilepticus in Rochester, Minnestoa 1965-1984. Neurology 1998; 50: 735-741

[65] Coeytaux A, Jallon P, Galobardes B et al. Incidence of status epilepticus in French-speaking Switzerland (EPISTAR). Neurology 2000; 55: 693-697

[66] Knake S, Rosenow F, Vescovi M et al. Incidence of status epilepticus in adults in Germany: A prospective, population-based study. Epilepsia 2001; 42: 714-718

[67] Vignatelli L, Tonon C, D’Alessandro R. Bologna Group for the Study of Status Epilepticus. Incidence and short-term prognosis of status epilepticus in adults in Bologna. Italy. Epilepsia 2003; 44: 964-968

[68] Rüegg S. Non-convulsive status epilepticus in adults: An overview. Schweiz Arch Neurol Psychiatrie 2008; 159: 53-83

[69] Rudin D, Grize L, Schindler C et al. High prevalence of nonconvulsive and subtle status epilepticus in an ICU of a tertiary care center: A three-year observational study. Epilepsy Res 2011; 96: 140-150 
[70] Privitera M, Hoffman M, Moore JL. Jester D. EEG detection of nontonic-clonic status epilepticus in patients with altered consciousness. Epilepsy Res 1994; 18: 155-166

[71] Alroughani R, Javidan M, Qasem A et al. Non-convulsive status epilepticus: the rate of occurrence in a general hospital. Seizure 2009; 18: 38-42

[72] Towne AR, Waterhouse E, Boggs JG et al. Prevalence of nonconvulsive status epilepticus in comatose patients. Neurology 2000; 54: 340-345

[73] Sutter R, Rüegg S, Kaplan PW. Epidemiology, diagnosis, and management of nonconvulsive status epilepticus - opening Pandora's box. Neurol Clin Pract 2012; 2: 275-286

[74] Kaplan PW. EEG criteria for nonconvulsive status epilepticus. Epilepsia 2007; 48 (Suppl 8): S39-S41

[75] Beniczky S, Hirsch L], Kaplan PW et al. Unified EEG terminology and criteria for nonconvulsive status epilepticus. Epilepsia 2013; 54 (Suppl 6): S28-S29

[76] Sutter R, Kaplan PW. Electroencephalographic criteria for nonconvulsive status epilepticus: Synopsis and comprehensive survey. Epilepsia 2012; 53 (Suppl 3): 1-51

[77] Hirsch L], LaRoche SM, Gaspard N et al. American Clinical Neurophysiological Society’s Standardized Critical Care EEG Terminology: 2012 version. J Clin Neurophysiol 2013; 30: 1-27

[78] Hauf M, Slotboom J, Nirkko A et al. Cortical regional hyperperfusion in nonconvulsive status epilepticus measured by dynamic brain perfusion CT. Am J Neuroradiol 2009; 30: 693-698
[79] Masterson K, Vargas MI, Delavelle J. Postictal deficit mimicking stroke: Role of perfusion CT. J Neuroradiol 2009; 36: 48-51

[80] Winkler DT, Fluri F, Fuhr P et al. Thrombolysis in stroke mimics: frequency, clinical characteristics, and outcome. Stroke 2009; 40: $1522-1525$

[81] Lansberg MG, O’Brien MW, Norbash AM et al. MRI abnormalities associated with partial status epilepticus. Neurology 1999; 52: 1021-1027

[82] Flacke S, Wüllner U, Keller E et al. Reversible changes in echo planar perfusion- and diffusion-weighted MRI in status epilepticus. Neuroradiology 2000; 42: 92-95

[83] Szabo K, Poepel A, Pohlmann-Eden B et al. Diffusion-weighted and perfusion MRI demonstrates parenchymal changes in complex partial status epilepticus. Brain 2005; 128: 1369-1376

[84] Huang YC, Weng HH, Tsai YT et al. Periictal magnetic resonance imaging in status epilepticus. Epilepsy Res 2009; 86: 72-81

[85] Katramados AM, Burdette D, Patel SC et al. Periictal diffusion abnormalities of the thalamus in partial status epilepticus. Epilepsia 2009; 50: 265-275

[86] Canas N, Breia P, Soares P et al. The elctroclinical-imagological spectrum and long-term outcome of transient periictal MRI abnormalities. Epilepsy Res 2010; 91: 240-252

[87] Cartagena AM, Young GB, Lee DH et al. Reversible and irreversible cranial MRI findings associated with status epilepticus. Epilepsy Behav 2014; 33: 24-30 